\title{
Hydrogen-bond-assisted symmetry breaking in a network of chiral metal- organic assemblies
}

\author{
Felix J. Rizzuto*, Patrick Pröhm*, Alex J. Plajer, Jake L. Greenfield, Jonathan R. Nitschke* \\ Department of Chemistry, University of Cambridge, Lensfield Rd CB2 1EW, UK \\ KEYWORDS: chirality, hydrogen bonding, metal-organic cages, heteroleptic
}

\begin{abstract}
Herein we elucidate the interplay of chiral, chelate, solvent and hydrogen-bonding information in the self-assembly of a series of new three-dimensional metal-organic architectures. Enantiopure ligands, each containing H-bond donors and acceptors, form different structures depending on the ratio in which they are combined: enantiopure components form $\mathrm{M}_{4} \mathrm{~L}_{4}$ assemblies, whereas racemic mixtures form $\mathrm{M}_{3} \mathrm{~L}_{3}$ stacks. Chiral amplification within $\mathrm{M}_{3} \mathrm{~L}_{3}$ enantiomers was observed when a 2:1 ratio of $R$ and $S$ subcomponent enantiomers was employed. Simply switching the solvent (from $\mathrm{MeCN}$ to $\mathrm{MeOH}$ ) or chelating unit (from bidentate to tridentate) increased the diversity of structures that can be generated from these building blocks, leading to the selective formation of novel $\mathrm{M}_{2} \mathrm{~L}_{2}$ and $\mathrm{M}_{3} \mathrm{~L}_{2}$ assemblies. The addition of achiral ligand building blocks resulted in the formation of further structures: When an achiral subcomponent was combined with its $R$ - and $S$ - chiral congeners, a three-layer heteroleptic architecture was generated, with the achiral unit sitting at the top of the stack. When combined with the $S$ enantiomer only, however, the achiral unit assembled in the center of the structure, thus demonstrating the selective placement of achiral units within chiral systems. Further sorting experiments revealed that combining $R$ and $S$ stereocenters within a single ligand led to diastereoselective product generation. These results show how geometric complementarity between different ligands impacts upon the degree of hydrogen bonding within the assembly, stabilizing specific lowsymmetry architectures from among many possible structural outcomes.
\end{abstract}

\section{INTRODUCTION}

Many discrete structures have been successfully prepared using metal-organic self-assembly, including planar polygons, ${ }^{1}$ Platonic ${ }^{2}$ and Archimedean ${ }^{3}$ solids, ${ }^{4}$ prisms,${ }^{5}$ ellipsoidal hosts 6 and spherical frameworks. ${ }^{7}$ These structures typically display high symmetry, as symmetry elements are defined during the formation of the directional bonds between polydentate ligands and metal centers. ${ }^{8}$ For hosts, function follows form: ${ }^{9}$ efficient guest binding, ${ }^{10}$ reactivity enhancement ${ }^{11}$ and catalysis ${ }^{12}$ rely on bound species fitting snugly within the cavities framed by specific architectural scaffolds. ${ }^{13}$ By understanding how the geometries and connection properties of the components of an assembly work together, high-symmetry structures can thus be synthesized with specific geometries. ${ }^{14}$

In contrast, the generation of low-symmetry architectures has proved more challenging: ${ }^{15}$ ligands tend to have rigid two-dimensional shapes, which give rise to rigid threedimensional structures. ${ }^{16}$ Low-symmetry ligands might be employed to generate desymmetrised structures; however, this method often generates polymers ${ }^{17}$ or complex mixtures of products ${ }^{18}$ owing to geometry mismatches. If flexible components are used, entropy often drives the formation of low-nuclearity products, ${ }^{19}$ or high-symmetry products form in unexpected ways. ${ }^{20}$

Secondary interactions have been shown to lower the symmetry during self-assembly: ${ }^{21}$ guest binding, ${ }^{22}$ steric crowding, ${ }^{23}$ aromatic interactions, ${ }^{24}$ and radical pairing ${ }^{25}$ have all been observed to contribute to the self-assembly of low-symmetry products. We hypothesized that hydrogenbonding sites within subcomponents might also favor the formation of lower-symmetry complexes. Hydrogen bonds are directional and complementary, and the strength of their interaction can be tuned by changing solvents. ${ }^{26} \mathrm{We}$ thus set out to investigate the effects of installing hydrogenbonding motifs on enantiopure $C_{3}$-symmetric subcomponents upon the symmetries of the products formed following self-assembly.

Our results show that the interplay between chiral recognition and hydrogen-bonding density dictate the stereochemistry of a new series of heteroleptic metal-organic complexes. Factors that include the presence of stereocenters, the solvent, and the degree of chelation (denticity) can stabilize one structure with respect to another. Transformations can thus be effected between four distinct assemblies, several of which can be generated in enantiopure form (Figure 1a). Our method thus allows the diastereoselective synthesis of a variety of asymmetrical and low-symmetry architectures by subcomponent self-assembly. We also demonstrate stereochemical amplification from sub-stoichiometric additions of enantiopure building blocks, and a means of using chirality and hydrogen-bonding information to dictate the number of building blocks incorporated per complex, and their connectivity. 
Enantiopure tetrahedra. Tetrahedron $(S)$-1 assembled from ( $S$ )-A (4 equiv), Zn(OTf) 2 (4 equiv) and 2-formylpyridine (P1, 12 equiv) in either $\mathrm{MeOH}$ or $\mathrm{CH}_{3} \mathrm{CN}$ (Supplementary Information Section 3.1). An ESI mass spectrum displayed peaks consistent with $\mathrm{Zn}^{\mathrm{II}}{ }_{4} \mathrm{~L}_{4}$ stoichiometry. The ${ }^{1} \mathrm{H}$ NMR spectrum was complex, displaying four times the number of signals expected for a $T$-symmetric tetrahedron (Figure 1b). This spectrum was consistent with two potential configurations, both having $C_{3}$ symmetry: either a structure in which all metal centers possess fac stereochemistry, but one has opposite handedness to the other three, or a structure composed of one fac and three mer vertices. MM3 molecular modelling of both configurations did not reveal an obvious energetic differentiation between these configurations (Figure S29).

Amide protons were observed in the region 7.5-8.3 ppm in the ${ }^{1} \mathrm{H}$ NMR spectrum of the assembly, suggesting that ligands were not participating in hydrogen bonding with each other. This precluded the possibility of a ligand arrangement in which ligands stacked on top of one another, as is observed in polymeric assemblies incorporating 1,3,5-tricarboxamide components. ${ }^{27}$

Multinuclear NMR studies provided evidence suggesting that 1 exists in a 3:1 mer:fac configuration, in a structure type first reported by Hooley. ${ }^{23 a}$ NOE correlations (Figure S28) were consistent with the presence of mer configurations for three of the four $\mathrm{Zn}^{\text {II }}$ centers, where pyridyl and phenylene rings stack in close contact. No such NOE correlations were observed between these environments in the

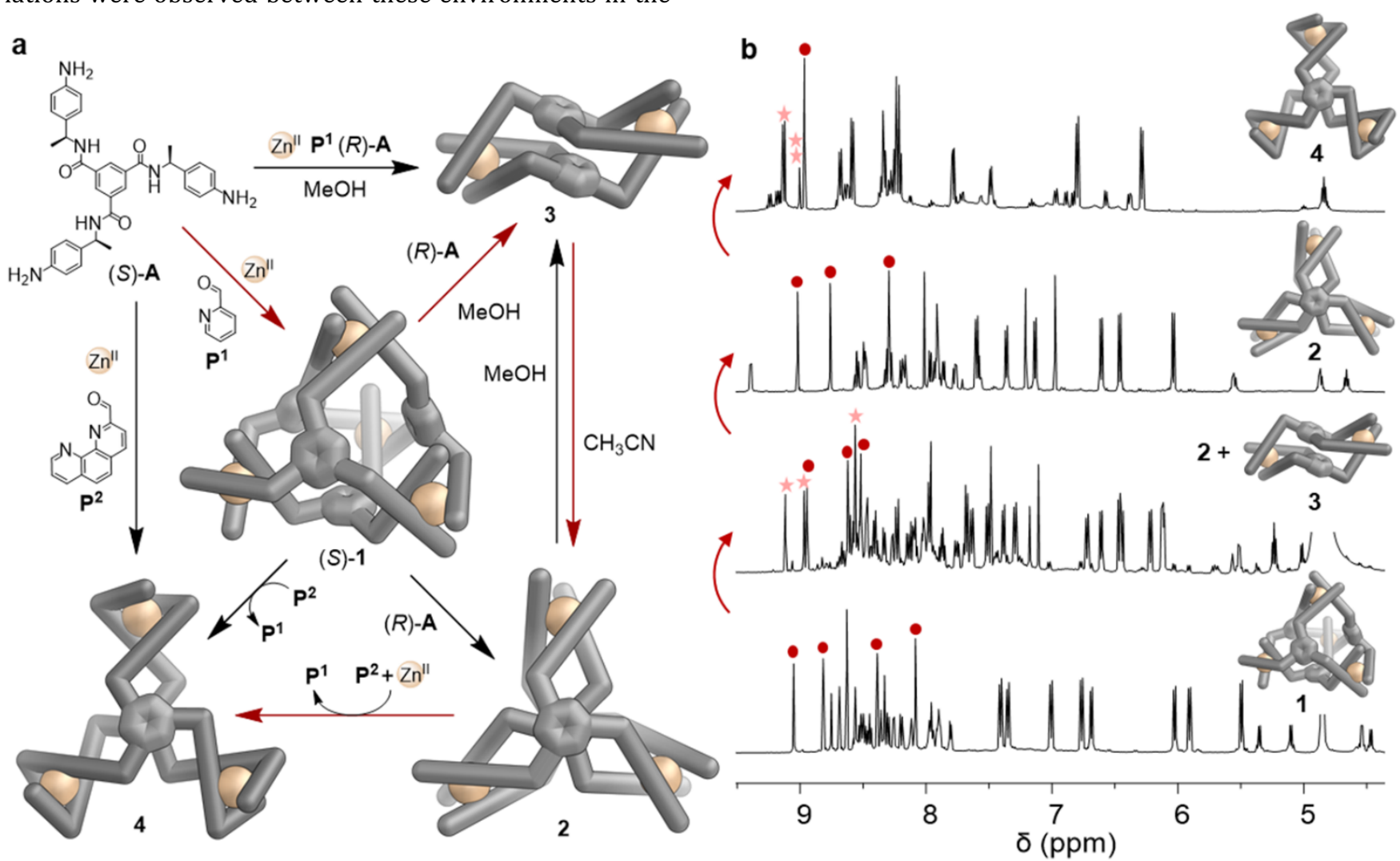

Figure 1. (a) Transformation pathways employing combinations of $(S)-\mathbf{A},(R)-\mathbf{A}, \mathbf{P}^{\mathbf{1}}, \mathbf{P}^{\mathbf{2}}$ and $\mathrm{Zn}^{11}$. All reactions occurred in MeCN unless otherwise indicated. (b) ${ }^{1} \mathrm{H}$ NMR spectra (500 MHz, $298 \mathrm{~K}$, MeOD for $\mathbf{1} \& \mathbf{3}, \mathrm{CD}_{3} \mathrm{CN}$ for 2\&4) showing the symmetries of products $\mathbf{1 - 4}$, with imine signals of the major and minor species marked with red dots and pink stars, respectively. Compound $\mathbf{1}$ transformed sequentially into $\mathbf{3}$, $\mathbf{2}$ and $\mathbf{4}$ following the pathway defined by red arrows in (a), after the application of the indicated stimuli. Full NMR assignments are available in the Supporting Information. fourth signal set, suggesting that this corner maintained fac geometry. ${ }^{1} \mathrm{H}-{ }^{13} \mathrm{C}$ HMBC correlations (Figure S16) between also consistent with this ligand configuration. The dispersed ${ }^{13} \mathrm{C}$ signals (Figure S12) also suggested mixtures of facial and meridional corners in the complex: diastereomers containing only fac metal centers typically show more tightly clustered ${ }^{13} \mathrm{C}$ signals. ${ }^{28}$

This structural configuration is enabled by the flexibility of the $(S)$-A subcomponents within $(S)$-1. We propose that $(S)$-1 exists in a 3:1 mer:fac conformation because the basal ligand partially fills the cavity volume, as compared to a larger cavity in an all-fac isomer. $(S)-\mathbf{1}$ would thus be more favored entropically, as it would contain fewer high-energy solvent molecules trapped within its cavity.

$(R)$-1 was also generated by employing $(R)$-A in place of $(S)$-A during the assembly process. The ${ }^{1} \mathrm{H}$ NMR and ESI mass spectra of $(R)-\mathbf{1}$ and $(S)-\mathbf{1}$ were identical, as anticipated. The enantiopurity of the assemblies was established by ${ }^{1} \mathrm{H}$ NMR titration of Lacour's ${ }^{n} \mathrm{Bu}{ }_{4} \mathrm{~N} \Delta$-TRISPHAT into a $\mathrm{CD}_{3} \mathrm{CN}$ solution of $(R)-\mathbf{1}$ or $(S) \mathbf{- 1}$. This anion resolves enantiomeric cations by forming diastereotopic ion pairs. ${ }^{29} \mathrm{We}$ observed shifting, but not splitting, of the proton signals of both $(R)-\mathbf{1}$ and $(S)$-1 during titration with $\Delta$-TRISPHAT, suggesting that $(R)-\mathbf{1}$ and $(S)-\mathbf{1}$ were enantiopure (Figures S30 and S31). Mirror-image Cotton effects were also observed by Circular Dichroism (CD) spectroscopy, consistent with $(R)$-1 being the enantiomer of $(S)-\mathbf{1}$ (Figures S17 and S27). the central phenyl protons and carbonyl ${ }^{13} \mathrm{C}$ signals were 
Generation of $\mathbf{2}$ by chiral recognition. NOESY NMR spectroscopy revealed the ligands of $(R)-\mathbf{1}$ to be labile in $\mathrm{MeCN}$, exchanging between four unique chemical environments slowly on the NMR timescale (Figure S21). When $(S)$-1 was added to an acetonitrile solution of $(R)-\mathbf{1}(1: 1$ ratio), followed by stirring at room temperature for $12 \mathrm{~h}$, we observed a simplification of the ${ }^{1} \mathrm{H}$ NMR spectrum, which now displayed only three unique sets of ligand proton signals (Figure 1b, Supplementary Information Section 3.2). Low- and high-resolution ESI-MS spectra indicated that 1 had transformed into 2, with a $\mathrm{Zn}_{3} \mathrm{II}_{3} \mathrm{~L}_{3}$ composition. The same ${ }^{1} \mathrm{H}$ NMR spectrum resulted when $(S)-\mathbf{A},(R)-\mathbf{A}$, $\mathrm{Zn}(\mathrm{OTf})_{2}$ and $\mathbf{P}^{1}$ were combined in $\mathrm{CD}_{3} \mathrm{CN}$ and heated to $70{ }^{\circ} \mathrm{C}$ for $12 \mathrm{~h}$.

A crystal of 2 was grown through diffusion of $i \operatorname{Pr}_{2} \mathrm{O}$ into a solution of 2 containing $\mathrm{CsCB}_{11} \mathrm{H}_{12}$ (3 equiv) in $\mathrm{CD}_{3} \mathrm{CN}$. X-ray diffraction revealed the structure to be composed of a stack of three ligands in which the enantiomers of $\mathbf{L}^{\mathbf{A}}$ alternate. One equivalent of $\mathbf{2}$ thus contains two $\mathbf{L}^{(R)-A}$ ligands sandwiching one $\mathbf{L}^{(S)}$-A ligand, with all three metal centers having fac stereochemistry and $\Delta$ handedness; its enantiomer is also present in the crystal (Figure 2). The metal centers of $\mathbf{2}$ describe an approximately equilateral triangle, with $\mathrm{Zn}^{\mathrm{II}_{-}}$ $\mathrm{Zn}^{\text {II }}$ distances of 17-18 $\AA$. The structure thus possesses idealized $C_{3}$ symmetry, consistent with its NMR spectrum, wherein each of the three arms on each ligand are in identical environments. Both the crystal structure and solution NMR spectra provide evidence for hydrogen bonding between amide groups on adjacent ligands, which reinforce the configuration of the stack (Figure 2c).

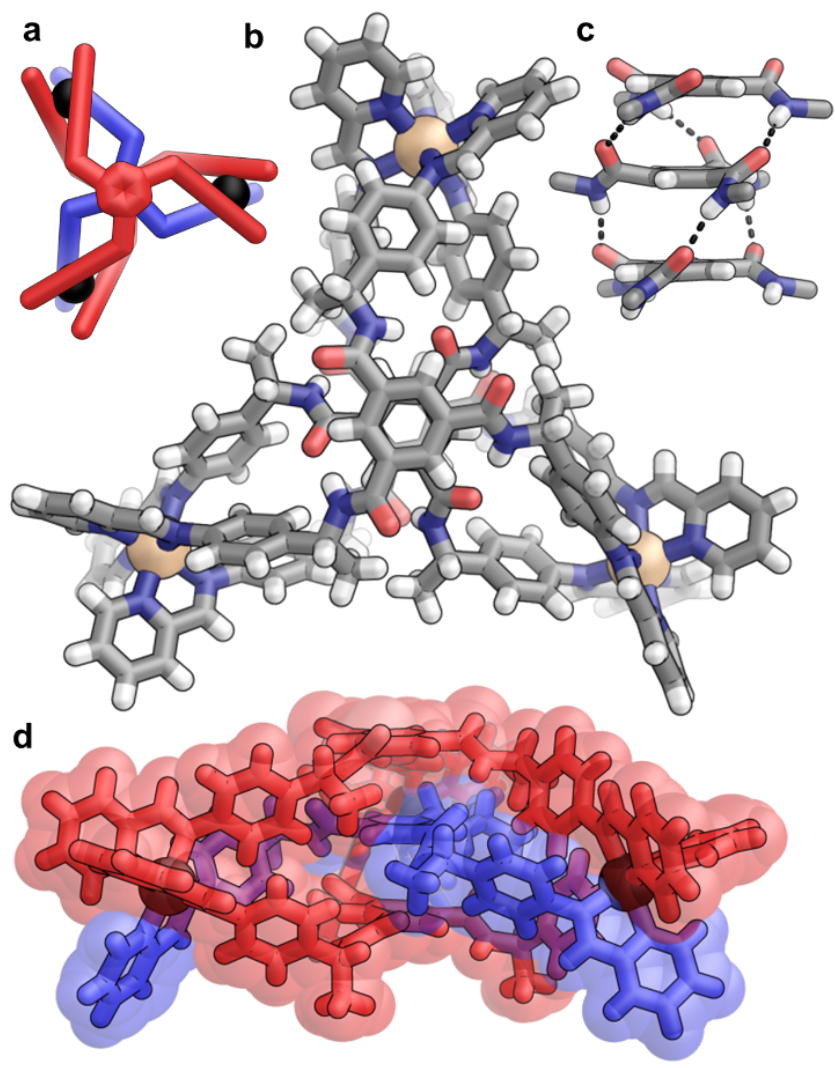

Figure 2. (a) Schematic representation of 2, showing the stereochemical configuration of a single enantiomer, where ligand arms containing $S$ stereocenters are blue, $R$ ligand arms are red and $\Delta$ metal centers are black. (b) X-ray crystal structure of 2 , viewed down the $C_{3}$ axis (anions and disorder removed for clarity; $\mathrm{Zn}^{\mathrm{II}}=$ yellow, $\mathrm{C}=$ gray, $\mathrm{N}=$ blue, $\mathrm{O}=$ red, $\mathrm{H}=$ white). (c) Hydrogen-bonding through the central column is highlighted with dashed black lines. (d) View of the structure perpendicular to its $C_{3}$ axis, color-coded as in (a).

Stereochemical amplification of 2 . The progressive addition of $(R)-\mathbf{1}$ to $(S) \mathbf{- 1}$ indicated complete formation of $\mathbf{2}$ following the addition of 0.5 equivalents of $(R)-1$ (Figure S41). This observation indicated that 2 could be obtained in enantiopure form from a $1: 2$ ratio of $R: S$ subcomponents. The $\Delta$-TRISPHAT anion was again employed to differentiate the enantiomers of $\mathbf{2}$ (Figure S42). When titrated with $\mathbf{2}$ that had been prepared using a 1:1 ratio of the two enantiomers of A, signal splitting and shifting was observed, consistent with the presence of the two enantiomers that were observed in the solid state. When titrated with $\mathbf{2}$ synthesized from a 1-to-2 ratio of $(S)$-A to $(R)$-A, however, no peak splitting was observed, consistent with the presence of only a single enantiomer. Cotton effects opposite in sign were observed in CD spectra for the two enantiomers prepared in this manner (Figure S43).

The addition of 3 equivalents of enantiopure $(S)-1$ to a racemic mixture of 4 equivalents of $(S R S)-2$ and 4 equivalents of $(R S R)$-2 generated 12 equivalents of enantiopure (SRS)-2 as the exclusive product (Figure 3 ). The addition of sub-stoichiometric amounts of enantiopure ligand to a racemic mixture thus produced an exclusively enantiopure product, in a stereochemical amplification event. ${ }^{30}$ This behavior stands in contrast to the normal case, wherein 1:2 mixtures of enantiomers generate a system of enantiomeric bias, corresponding to $33 \%$ ee. ${ }^{31}$ Here, $100 \%$ ee is observed when a $1: 2$ ratio of $R$ and $S$ ligands is employed. This reaction is thus both diastereo- and enantio-selective.

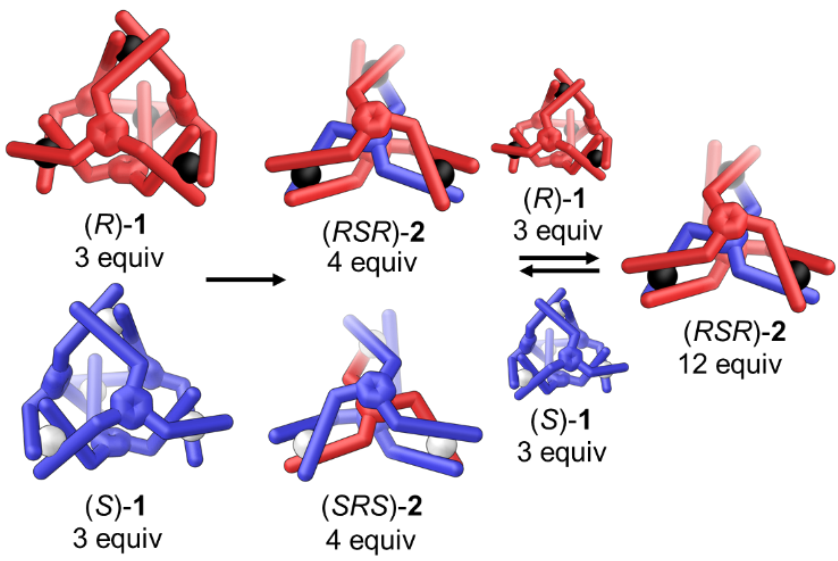

Figure 3. Stereochemical amplification of $\mathbf{2}$ from the sub-stoichiometric addition of $\mathbf{1}$. Initially, combining equimolar quantities of $(R)$-1 and $(S)-\mathbf{1}$ generated equimolar quantities of $(S R S)-2$ and $(R S R)-2$. The subsequent addition of $3 / 8$ of an equivalent of $(R)-1$ to this mixture produced $(R S R)-2$ exclusively. The racemic mixture of 2 could be regenerated by adding $(S)-\mathbf{1}$.

Solvent-induced reorganization. When a $1: 1$ ratio of $(R)-\mathbf{A}:(S)$-A was combined with Zn(OTf $)_{2}$ and $\mathbf{P}^{\mathbf{1}}$ in $\mathrm{MeOH}$ instead of MeCN, a combination of $\mathbf{2}$ and new structure $\mathbf{3}$ were formed. ESI-MS analysis indicated a $\mathrm{Zn}^{\mathrm{II}_{2}} \mathrm{~L}_{2}$ composition for 3 (Supplementary Information Section 3.3). The ${ }^{1} \mathrm{H}$ NMR spectrum of the mixture of $\mathbf{2}$ and $\mathbf{3}$ displayed six sets of NMR signals (Figure 1b), corresponding to three distinct ligand 
environments in each of 2 and 3. Upon dilution from $3.5 \mathrm{mM}$ to $0.35 \mathrm{mM}$, the signals attributed to 2 decreased in intensity, leaving $\mathbf{3}$ as the dominant product, as confirmed by ESIMS. Thus, upon dilution, the equilibrium between $\mathbf{2}$ and $\mathbf{3}$ shifts toward entropically-favorable 3.

Diffusion of $\mathrm{Et}_{2} \mathrm{O}$ into a dilute methanol solution of $\mathbf{3}$ produced a crystal suitable for X-ray diffraction (Figure 4). In this meso structure, two arms of one ligand and one arm of another meet at each metal center. The structure possesses an inversion center, lending $3 C_{\mathrm{i}}$ symmetry, with both $\mathrm{Zn}^{\mathrm{II}}$ centers having fac stereochemistry but opposite handedness. Both enantiomers of $\mathbf{A}$ are thus incorporated into a single achiral structure. Two hydrogen bonds between enantiomeric pairs of ligands flank the inversion center (Figure 4c).

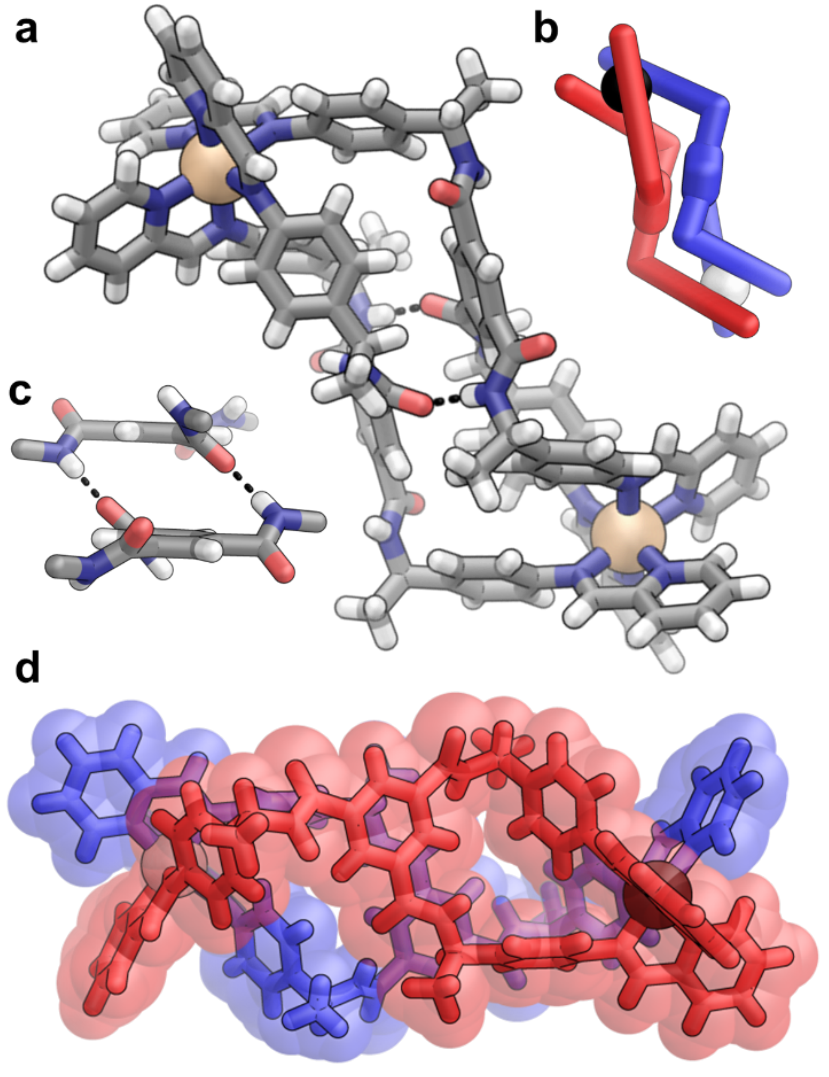

Figure 4. (a) X-ray crystal structure of 3, with hydrogen bonding highlighted with dashed black lines (anions and solvent removed for clarity; $\mathrm{Zn}^{\mathrm{II}}=$ yellow, $\mathrm{C}=$ gray, $\mathrm{N}=$ blue, $\mathrm{O}=$ red, $\mathrm{H}=$ white). (b) Schematic representation of $3\left(S\right.$ ligand arms = blue, $R$ ligand arms = red, $\Delta-\mathrm{Zn}^{\mathrm{II}}=$ black, $\Lambda-\mathrm{Zn}^{\mathrm{Il}}=$ white). (c) Hydrogen-bonding between ligands is shown with dashed black lines. (d) View perpendicular to (a), with colors indicating stereochemistry as in (b).

Product $\mathbf{2}$ transformed into $\mathbf{3}$ when the $\mathrm{MeOH}$ solvent was removed and the residue was redissolved in MeCN. This process was reversible: redissolution of isolated 2 in $\mathrm{MeOH}$ generated 3.

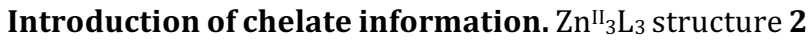

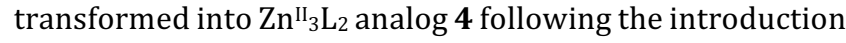
of 2-formylphenanthroline $\mathbf{P}^{2}$ and additional $\mathrm{Zn}^{\text {II }}$ (Figure 1a, Supplementary Information Section 3.4). This subcomponent substitution process thus resulted in the replacement of the bidentate ligand termini of $\mathbf{2}$ with tridentate coordinating groups. We infer the driving force for this substitution to derive from the principle of coordinative saturation, whereby the thermodynamically most favorable set of products contains the largest number of metal-ligand bonds. ${ }^{32}$ Although the ESI mass spectrum of 4 (Figure S62) displayed only signals attributable to a $\mathrm{Zn}^{\mathrm{II}_{3} \mathrm{~L}_{2}}$ product composition, the ${ }^{1} \mathrm{H}$ NMR spectrum (Figure S64) was complex, suggesting the formation of multiple diastereomers.

When enantiopure $(S)$-A was combined with $\mathbf{P}^{\mathbf{2}}$ and $\mathrm{Zn}(\mathrm{OTf})_{2}$, a better-defined ${ }^{1} \mathrm{H}$ NMR spectrum, with fewer signals, was observed (Figure $1 \mathrm{~b}$ ). A high-symmetry species with one set of ${ }^{1} \mathrm{H}$ signals, and a secondary species, having three times as many signals, were identified. We attribute the higher-symmetry species to a $\Delta \Delta \Delta / \Lambda \Lambda \Lambda D_{3}$-symmetric $\mathrm{Zn}^{\mathrm{II}} \mathrm{L}_{2}$ architecture, and the lower-symmetry one to its $\Delta \Delta \Lambda / \Lambda \Lambda C_{2}$-symmetric diastereomer (Figure S55). The presence of two diastereomers is supported by the observations that the ${ }^{13} \mathrm{C}$ signals for each proton environment are clustered in the ${ }^{1} \mathrm{H}-{ }^{13} \mathrm{C}$ HSQC spectrum (Figure S58), and that all proton signals diffused at the same rate by ${ }^{1} \mathrm{H}$ DOSY NMR spectroscopy (Figure S61).

Integration of the ${ }^{1} \mathrm{H}$ NMR spectrum of the assembly indicated a 1:1 ratio of $D_{3}-4: C_{2}-4$ in solution. A statistical distribution of $\Lambda$ - and $\Delta-Z^{I I}$ stereocenters within the product mixture would correspond to a $1: 3$ ratio of $D_{3}-\mathbf{4}: C_{2}-\mathbf{4}$, suggesting that the $D_{3}$-symmetric isomer is favored during assembly. The presence of diastereomers also explains the complexity of the NMR spectra of the assembly formed from a racemic mixture of $(S)$-A and $(R)$-A, wherein additional signals corresponding to the integration of both $S$ and $R$ ligands into an $\mathrm{M}^{\mathrm{II}}{ }_{3} \mathrm{~L}_{2}$ framework were observed.

The observation of all amide signals of both diastereomers around $\delta=7.5 \mathrm{ppm}$ (Figure S55) suggested that no hydrogen bonding occurred between ligands in this assembly. ${ }^{33}$ We thus infer the presence of ligand configurations in which $\mathrm{NH}$ and $\mathrm{CO}$ moieties on different ligands are not within hydrogen-bonding distance within these assemblies.

Self-assembly from achiral building blocks. When B (an achiral derivative of $\mathbf{A}$ ), $\mathrm{Zn}(\mathrm{OTf})_{2}$ and $\mathbf{P}^{\mathbf{1}}$ were heated at $70{ }^{\circ} \mathrm{C}$ for $12 \mathrm{~h}$ in $\mathrm{MeCN}$, product 5 , having a $\mathrm{Zn}^{\mathrm{II}}{ }_{3} \mathrm{~L}_{3}$ composition, was identified by ESI-MS (Figure 5a, Supplementary Information Section 3.5). Nine sets of signals were observed in the ${ }^{1} \mathrm{H}$ NMR spectrum of $\mathbf{5}$, having equal intensities. ${ }^{1} \mathrm{H}-$ ${ }^{13} \mathrm{C} \mathrm{HSQC}$ and HMBC spectra furthermore indicated that the central phenyl protons on each ligand were chemically inequivalent (each ligand displayed ${ }^{4} \mathrm{~J}$ coupling to nearestneighbor protons on the same ring), suggesting threefold desymmetrization of each ligand within 5. These spectra suggest that each ligand arm within the assembly is magnetically unique, and that the structure is desymmetrised, as compared to $C_{3}$-symmetric $\mathbf{2}$.

Each of the benzylic protons of the $\mathbf{B}$ residues within $\mathbf{5}$ was rendered diastereotopic, consistent with a stacked configuration similar to the one observed in 2 . All amide proton signals assigned to the central ligand were shifted downfield, suggesting participation in hydrogen bonding. The central-phenyl-ring proton signals were shifted upfield, which we infer to be a consequence of shielding by the ligands on either side. NOESY cross-peaks attributed to chemical exchange were observed between the six environments 
assigned to the top and bottom ligands, suggesting that these components are exchanging positions slowly on the NMR timescale.

The lack of symmetry of $\mathbf{5}$ suggested a configuration in which the $\Lambda \Lambda \Delta / \Delta \Delta \Lambda$ diastereomer was generated exclusively, in contrast to 2 , which contains all metal centers of the same handedness. The structure-directing effects of hydrogen-bonding between amide groups, as evidenced by the presence of signals at $\delta>10 \mathrm{ppm}$ (Figure S66), along with removal of the steric bulk of the methyl groups attached to the stereogenic centers in A, thus led to symmetry-breaking within this $\mathrm{M}_{3} \mathrm{~L}_{3}$ assembly.
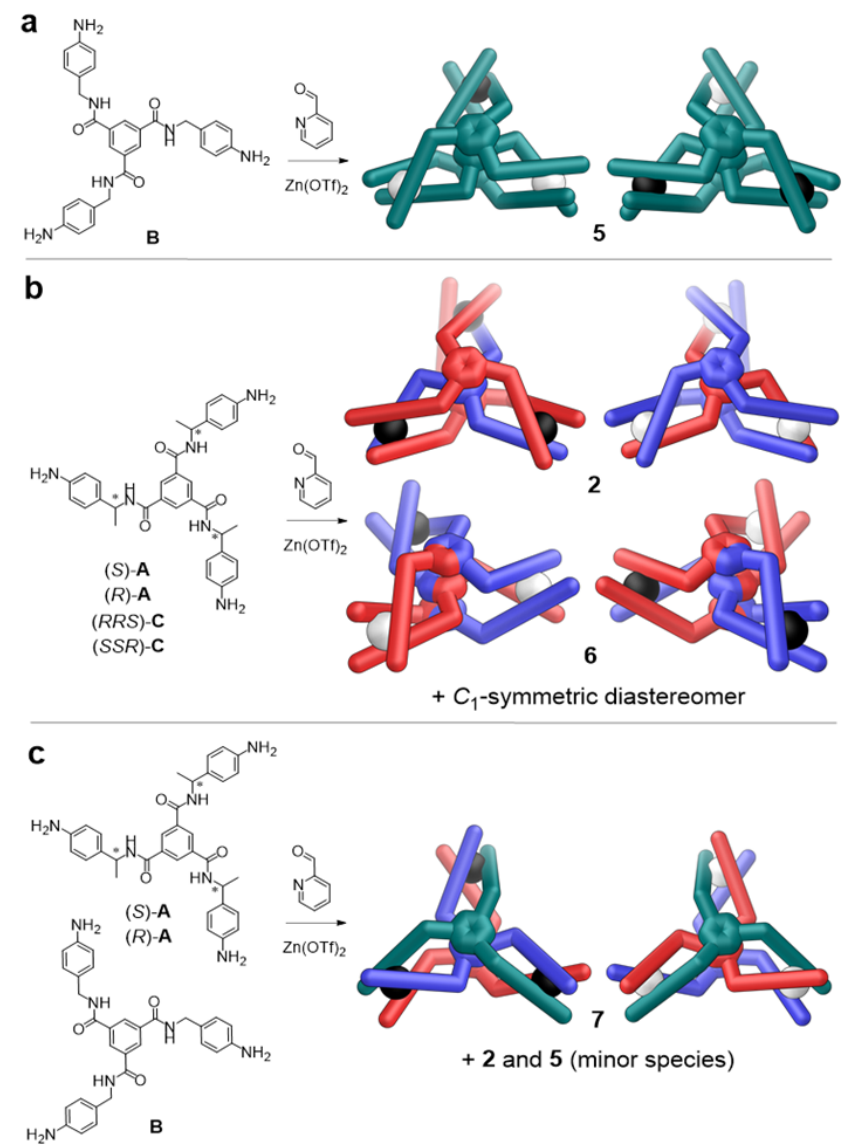

Figure 5. Sorting experiments to generate heteroleptic architectures (where $S$ ligand arms = blue, $R$ ligand arms = red, ligand arms containing no stereocenters $=$ green, $\Delta-\mathrm{Zn}^{\mathrm{II}}=$ black and $\Lambda-\mathrm{Zn}^{\mathrm{II}}=$ white). (a) Generation of a $\Lambda \Lambda \Delta / \Delta \Delta \Lambda \mathrm{M}_{3} \mathrm{~L}_{3}$ diastereomer 5 from an achiral ligand. (b) Only three species were observed from the reaction of four different ligands with different stereochemical configurations, of which 2 and $\mathbf{6}$ were structurally characterized. (c) A heteroleptic, homochiral complex $\mathbf{7}$ incorporating each of $(S)$-A, $(R)$-A and B self-assembled selectively.

Sorting experiments with a racemic ligand. Subcomponent A contains three stereocenters with either the $(R, R, R)$ or $(S, S, S)$ configuration. We envisioned that a ligand with mixed stereocenters might diversify the number of product structures obtained (Supplementary Information Section 5.1).

We thus synthesized a diastereomeric mixture of derivatives of $\mathbf{A}$, containing a mixture of both $(R)$-A and $(S)$ - $\mathbf{A}$, as well as the new subcomponents $(R, R, S)-\mathbf{C}$ and $(S, S, R)-\mathbf{C}$. $\mathbf{C}$ is a diastereomer of $\mathbf{A}$, wherein the arms of $\mathbf{C}$ have either two
$R$ and one $S$, or two $S$ and one $R$, stereocenters. The distribution of diastereomers within this mixture thus reflected statistical incorporation of $(R)$ and $(S)$ stereocenters. The reaction of this mixture of subcomponents with $\mathrm{Zn}(\mathrm{OTf})_{2}$ and $\mathbf{P}^{\mathbf{1}}$ provided a product mixture with a sharp ${ }^{1} \mathrm{H}$ NMR spectrum; its ESI mass spectrum was consistent with the exclusive formation of $\mathrm{Zn}^{\mathrm{II}} \mathrm{L}_{3}$ products (Figure $5 \mathrm{~b}$ ).

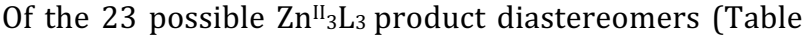
S1), only three could be observed by NMR spectroscopy; a ${ }^{1} \mathrm{H}-{ }^{13} \mathrm{C}$ HSQC spectrum revealed 21 unique ligand environments (Figure S84). This corresponds to the formation of three products: one with $C_{3}$ symmetry ( 2 , three sets of signals) and two having $C_{1}$ symmetry (each with 9 sets of signals = 18 signal sets) (Figure S83)

Slow diffusion of $\mathrm{Et}_{2} \mathrm{O}$ into this mixture of products containing $n \mathrm{Bu}_{4} \mathrm{NBF}_{4}$ (10 equiv) produced a crystal of product 6 suitable for X-ray diffraction analysis (Figure 6). This complex is similar to 2 , but is composed exclusively of the heterochiral subcomponents $(R, R, S)$-C and $(S, S, R)$-C. The triangle formed by its three $\mathrm{Zn}^{\mathrm{II}}$ centers is scalene, as compared to equilateral 2 . Its core is reinforced by three intramolecular hydrogen bonds between adjacent amides (Figure 6c). One metal center has the opposite handedness to the other two, and both enantiomers are present in the crystal.

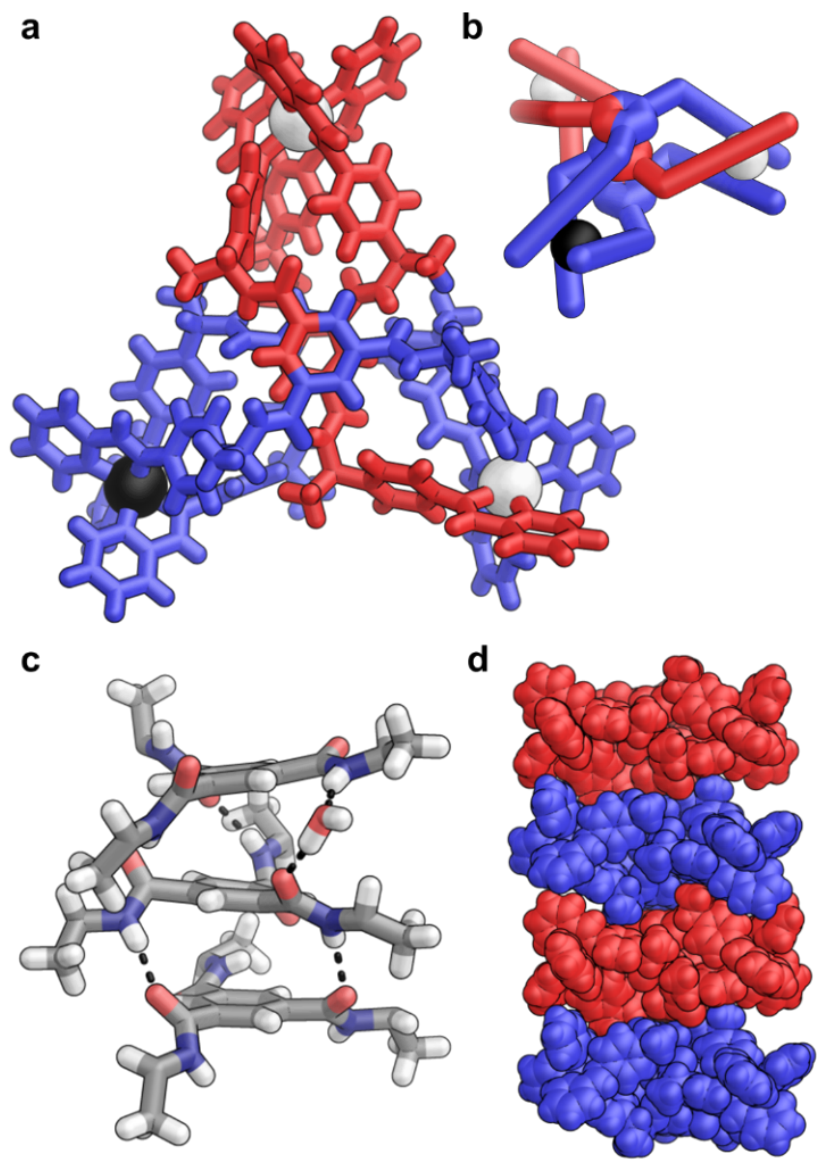

Figure 6. (a) X-ray crystal structure of 6, with colors highlighting the stereochemistry of each ligand arm and metal center $(S$ ligand arms $=$ blue, $R$ ligand arms = red, $\Delta-\mathrm{Zn}^{\mathrm{II}}=$ black, $\Lambda-\mathrm{Zn}^{\mathrm{II}}=$ white; anions, solvent and disorder removed for clarity). (b) Cartoon representation of (a). (c) Three intramolecular, and two intermolecular (with a bridging $\mathrm{H}_{2} \mathrm{O}$ molecule), hydrogen bonds reinforce the core of $\mathbf{6}$ (dashed black lines). 
(d) The crystal packing of $\mathbf{6}$ shows stacking of opposite enantiomers of 6, promoted by three intermolecular hydrogen bonds.

In the solid state, three intermolecular hydrogen bonds reinforce columnar aggregations of enantiomers of $\mathbf{6}$ along the $c$-axis (Figure $6 \mathrm{~d}$ ). These stacks are reminiscent of the polymeric architectures described by Meijer and coworkers. ${ }^{34}$

Optimization of heteroleptic product formation. Structurally complex heteroleptic assemblies reminiscent of 2 resulted from the combination enantiopure and achiral ligands during self-assembly (Supplementary Information Section 5.2). A $1: 1: 1$ ratio of $(S)$-A : $(R)$-A : B generated 7 as the major product (in 79\% yield by NMR integration, relative to minor amounts of homoleptic 2 and 5). Assembly 7 incorporates residues of $(S)-\mathbf{A},(R)$-A and $\mathbf{B}$ together into a heteroleptic $\mathrm{M}_{3} \mathrm{~L}_{3}$ assembly (Figure $5 \mathrm{c}$ ). The ${ }^{1} \mathrm{H}$ NMR spectrum of 7 (Figure S85) was sharp, with only three sets of signals, suggesting that each ligand maintained its threefold symmetry upon integration into heteroleptic 7. NMR experiments (Figures S85-S91) verified that the B residues occupied an outward-facing position within 7 , with their NH donors not participating in intramolecular H-bonding.

The proposed solution state configuration was reflected in the crystal structure of 7: a three-tier heteroleptic complex containing each of the distinct subcomponent residues (Figure 7). Both 2 and 7 co-crystallized in a disordered configuration, reflecting their similar morphologies. Indeed, 7 showed the same hydrogen bonding configuration as observed in $\mathbf{2}$ (Figure 2). Both enantiomers of $\mathbf{7}$ were observed in the crystal.

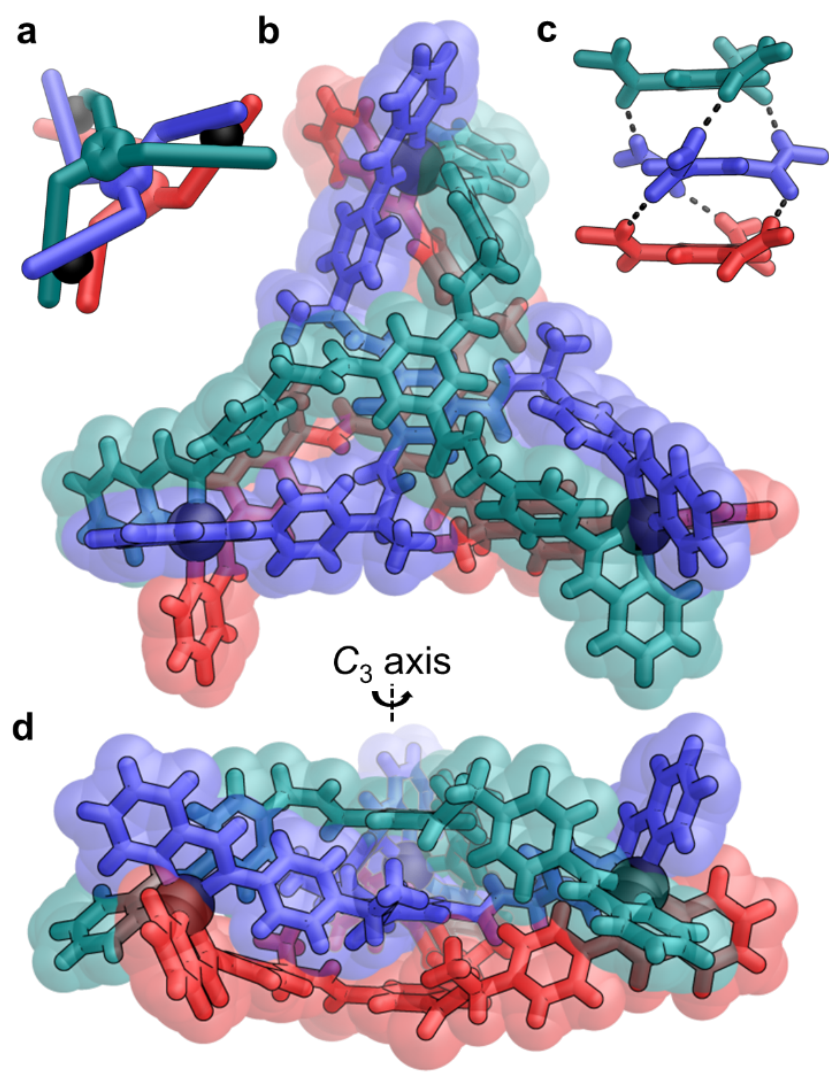

Figure 7. (a) Schematic representation of 7, showing a single enantiomer, where ligands derived from $S$-A are blue, ligands derived from $R$ -
A are red, ligands derived from achiral $\mathbf{B}$ are green, and $\Delta-\mathrm{Zn}^{\mathrm{II}}$ centers are black. (b) X-ray crystal structure of 7, viewed offset from the top of the structure. (c) Hydrogen bonds through the central core, highlighted with dashed black lines. (d) View of the structure perpendicular to the $C_{3}$ axis. Anions, solvent and disorder have been removed for clarity.

To further verify that $\mathbf{7}$ incorporated both $(R)$-A and $(S)$-A in solution, as opposed to a single enantiomer, control sorting experiments, wherein only $(S)$-A and $\mathbf{B}$ were combined in different ratios $(1: 3,1: 2,1: 1$ and 2:1) during assembly, were conducted (Supplementary Information Section 5.2). A mixture of heteroleptic $\mathrm{M}_{4} \mathrm{~L}_{4}$ and $\mathrm{M}_{3} \mathrm{~L}_{3}$ species were observed by ESI-MS in each case. Importantly, no ${ }^{1} \mathrm{H}$ NMR signals attributed to 7 were observed during these sorting experiments, confirming that $\mathbf{7}$ incorporates equimolar amounts of $(R)$-A, $(S)$-A and $\mathbf{B}$ in solution.

Further NMR and ESI-MS examination of the sorted output from a 2:1 reaction of $(S)$-A and $\mathbf{B}$ revealed that different ligands could be accommodated into different metal:ligand configurations: one heteroleptic tetrahedron $\left(\mathrm{Zn}^{\mathrm{II}} \mathbf{L}^{\left.(S)-\mathbf{A}_{3} \mathbf{L}^{\mathrm{B}}\right)}\right.$

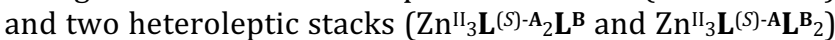
were observed (Figure S94). The presence of an amide triplet at $\delta=9.7 \mathrm{ppm}$ in the ${ }^{1} \mathrm{H}$ NMR spectrum of this reaction

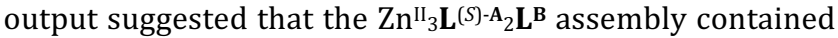
$\mathbf{L}^{\mathbf{B}}$, which contains no stereocenters, as its central ligand (Figure S95). This configuration contrasts with $\mathbf{7}$, where $\mathbf{L}^{\mathbf{B}}$ sits at an externally-facing site. This ability to control the position of achiral components within chiral self-assembled structures could lead to preferential and site-specific interactions with enantiopure or asymmetric compounds.

\section{CONCLUSIONS}

Different inputs of chiral, chelate and solvent information led to the expression of different structural outputs (Table 1). Distinct ligand enantiomers formed different supramolecular geometries than their racemic mixtures, and achiral subcomponents displayed different stereochemical outputs than their chiral congeners. By modulating the degree and nature of the chiral information present in each assembly, distinct product outputs resulted, leading to the selective generation of specific diastereomers from among large collections of possible product structures, including the selective formation of heteroleptic assemblies. Of particular interest is the distinctly different assembly behavior displayed by enantiopure ligands, which contrasted strongly with their racemic counterparts: for instance, employing only $(S)$-A produced $\mathbf{1}$, whereas combining $(S)$-A with $(R)$-A produced $\mathbf{2}$ or $\mathbf{3}$. Furthermore, the formation of enantiopure structures was observed from 1:2 mixtures of $R: S$ isomers, indicative of chiral amplification upon self-assembly. These results thus reflect the increased diversity in product structures that accompanies the use of an expanded chiral pool. ${ }^{35}$

Table 1. Summary of the structures observed from combinations of ligands, where enantiopure structures are colored blue. 


\begin{tabular}{|c|c|c|c|c|c|c|c|}
\hline \multirow{2}{*}{\multicolumn{2}{|c|}{ equiv }} & \multicolumn{2}{|c|}{$(S)-\mathbf{A}$} & \multicolumn{2}{|c|}{$(R)-\mathbf{A}$} & B & $(r a c)-\mathbf{A}$ \\
\hline & & 1 & 2 & 1 & 2 & 1 & 2 \\
\hline \multirow{2}{*}{$(S)-\mathbf{A}$} & 1 & $(S)-1$ & $(S)-1$ & 2 & $(R S R)-2$ & $a$ & (SRS)-2 \\
\hline & 2 & & $(S)-1$ & $(S R S)-2$ & 2 & $a$ & $(S)-1+2$ \\
\hline$(R)-\mathbf{A}$ & 1 & & & $(R)-1$ & $(R)-1$ & $a^{\prime}$ & $(R S R)-2$ \\
\hline B & 1 & & & & & 5 & 7 \\
\hline (rac)-A & 2 & & & & & & 2 \\
\hline
\end{tabular}

$\boldsymbol{a}=$ mixture of products, where $a^{\prime}$ is the enantiomer set of $a$.

Our crystallographic investigations suggest that the chirality $(R$ or $S$ ) of the ligand impacts directly upon the handedness of the coordinated metal center $(\Lambda$ or $\Delta)$. For instance, a metal center chelated by two $R$ and one $S$ ligand arm generated only $\Delta$ corners in all of 2, 3 and 6; likewise, two $S$ and one $R$ ligand arms resulted in a $\Lambda$ corner. When achiral B was introduced into 7, the stereochemical information from the one $S$ and the one $R$ ligand balanced out, resulting in no stereochemical influence upon the metal corners.

The degree of hydrogen bonding observed within these structures results from geometric complementarity between subcomponents held in specific stereochemical orientations by metal coordination. Intra-complex hydrogen bonding favored the formation of specific isomers. When hydrogen-bonding was absent (as in $\mathbf{4}$, for instance), multiple diastereomers were evident; when hydrogen-bonding was promoted (as in 2, 5, 6 and 7), strong diastereomeric selectivity was observed. Within the set of complexes studied, metal coordination thus served to dictate the shape of the overall framework, following the principle of coordinative saturation, ${ }^{32}$ and hydrogen-bonding served to fix the stereochemistry where possible.

Our results chart, for the first time, the processing of stereochemical information within mixtures of enantiopure, racemic and achiral building blocks simultaneously in the generation of metal-organic architectures. This study provides new means to transform species selectively, generate heteroleptic structures, and improve the specificity of sorting reactions, and provides insight into the importance of ligand symmetry, stereochemistry and intramolecular hydrogen bonding as driving forces in determining structure.

\section{ASSOCIATED CONTENT}

Supporting Information: synthetic details, characterization data, sorting experiments and crystallographic details. This material is available free of charge via the Internet at http://pubs.acs.org.

$\mathrm{X}$-ray data for $\mathbf{2}$ (CCDC 1877024)

$\mathrm{X}$-ray data for 3 (CCDC 1877023)

X-ray data for 6 (CCDC 1877025)

X-ray data for $7 / 2$ co-crystal (CCDC 1877026)

\section{AUTHOR INFORMATION}

\section{Corresponding Author}

*jrn34@,cam.ac.uk

ORCID

Felix J. Rizzuto 0000-0003-2799-903X

Patrick Pröhm 0000-0002-3318-9941
Jake L. Greenfield 0000-0002-7650-5414

Jonathan R. Nitschke 0000-0002-4060-5122

\section{Author Contributions}

$\$$ These authors contributed equally.

\section{Funding Sources}

This work was supported by the European Research Council (695009) and the UK Engineering and Physical Sciences Research Council (EPSRC, EP/P027067/1 and EP/M506242/1).

\section{ACKNOWLEDGMENTS}

We thank Cambridge Australia Scholarships (FJR), the Erasmus+ Programme (PP), the Cambridge Trust (FJR \& AJP) and the PPF (AJP) for PhD funding. We thank Diamond Light Source for synchrotron time at Beamline I19 (MT15768), and the EPSRC UK National Mass Spectrometry Facility at Swansea for mass spectrometric analyses.

\section{REFERENCES}

(1) (a) Yin, G.-Q., Wang, H., Wang, X.-Q., Song, B., Chen, L.-J., Wang, L., Hao, X.-Q., Yang, H.-B., Li, X., Self-assembly of emissive supramolecular rosettes with increasing complexity using multitopic terpyridine ligands. Nat. Commun. 2018, 9, 567; (b) Drożdż, W., Walczak, A., Bessin, Y., Gervais, V., Cao, X.-Y., Lehn, J.-M., Ulrich, S., Stefankiewicz, A. R., Multivalent metallosupramolecular assemblies as effective DNA binding agents. Chem. - Eur. J. 2018, 24, 10802-10811; (c) Ruben, M., Rojo, J., Romero-Salguero, F. J., Uppadine, L. H., Lehn, J.-M., Gridtype metal ion architectures: Functional metallosupramolecular arrays. Angew. Chem. Int. Ed. 2004, 43, 3644-3662; (d) Hogue, R. W., Dhers, S., Hellyer, R. M., Luo, J., Hanan, G. S., Larsen, D. S., Garden, A. L., Brooker, S., Selfassembly of cyclohelicate [ $\left.\mathrm{M}_{3} \mathrm{~L}_{3}\right]$ triangles over [M4 $\left.\mathrm{M}_{4}\right]$ qquares, despite near-linear bis-terdentate $\mathrm{L}$ and octahedral M. Chem. Eur. J. 2017, 23, 14193-14199; (e) Dolinar, B. S., Alexandropoulos, D. I., Vignesh, K. R., James, T. A., Dunbar, K. R., Lanthanide triangles supported by radical bridging ligands. $J$. Am. Chem. Soc. 2018, 140, 908-911; (f) Frischmann, P. D., Guieu, S., Tabeshi, R., MacLachlan, M. J., Columnar organization of head-to-tail self-assembled $\mathrm{Pt}_{4}$ rings. J. Am. Chem. Soc. 2010, 132, 7668-7675.

(2) (a) Sanz, S., O'Connor, H. M., Pineda, E. M., Pedersen, K. S., Nichol, G. S., Mønsted, O., Weihe, H., Piligkos, S., McInnes, E. J. L., Lusby, P. J., Brechin, E. K., [Crill8 $\left.\mathrm{M}^{\mathrm{II}}\right]^{12+}$ coordination cubes $\left(\mathrm{M}^{\mathrm{II}}=\mathrm{Cu}, \mathrm{Co}\right)$. Angew. Chem. Int. Ed. 2015, 54, 6761-6764; (b) Ramsay, W. J., Rizzuto, F. J., Ronson, T. K., Caprice, K., Nitschke, J. R., Subtle ligand modification inverts guest binding hierarchy in M ${ }^{118} \mathrm{~L} 6$ supramolecular cubes. J. Am. Chem. Soc. 2016, 138, 7264-7267.

(3) (a) Rizzuto, F. J., Nitschke, J. R., Stereochemical plasticity modulates cooperative binding in a $\mathrm{Co}^{\mathrm{II} 12} \mathrm{~L} 6$ cuboctahedron. Nat. Chem. 2017, 9, 903; (b) Leininger, S., Fan, J., Schmitz, M., Stang, P. J., Archimedean solids: Transition metal mediated rational self-assembly of supramolecular-truncated tetrahedra. Proc. Natl. Acad. Sci. U.S.A. 2000, 97, 1380-1384.

(4) Ward, M. D., Polynuclear coordination cages. Chem. Commun. 2009, 4487-4499.

(5) (a) Yu, G., Yu, S., Saha, M. L., Zhou, J., Cook, T. R., Yung, B. C., Chen, J., Mao, Z., Zhang, F., Zhou, Z., Liu, Y., Shao, L., Wang, S., Gao, C., Huang, F., Stang, P. J., Chen, X., A discrete organoplatinum(II) metallacage as a multimodality theranostic 
platform for cancer photochemotherapy. Nat. Commun. 2018, 9, 4335; (b) Zhang, M., Saha, M. L., Wang, M., Zhou, Z., Song, B., Lu, C., Yan, X., Li, X., Huang, F., Yin, S., Stang, P. J., Multicomponent platinum(II) cages with tunable emission and amino acid sensing. J. Am. Chem. Soc. 2017, 139, 5067-5074; (c) Sun, L.-Y., Sinha, N., Yan, T., Wang, Y.-S., Tan, T. T. Y., Yu, L., Han, Y.-F., Hahn, F. E., Template synthesis of three-dimensional hexakisimidazolium cages. Angew. Chem. Int. Ed. 2018, 57, 5161-5165; (d) Luo, D., Zhou, X.-P., Li, D., Beyond molecules: Mesoporous supramolecular frameworks self-assembled from coordination cages and inorganic anions. Angew. Chem. Int. Ed. 2015, 127, 6288-6293.

(6) (a) Clever, G. H., Punt, P., Cation-anion arrangement patterns in self-assembled $\mathrm{Pd}_{2} \mathrm{~L}_{4}$ and $\mathrm{Pd}_{4} \mathrm{~L}_{8}$ coordination cages. Acc. Chem. Res. 2017, 50, 2233-2243; (b) Yamashina, M., Akita, M., Hasegawa, T., Hayashi, S., Yoshizawa, M., A polyaromatic nanocapsule as a sucrose receptor in water. Sci. Adv. 2017, 3.

(7) Fujita, D., Ueda, Y., Sato, S., Mizuno, N., Kumasaka, T., Fujita, M., Self-assembly of tetravalent Goldberg polyhedra from 144 small components. Nature 2016, 540, 563.

(8) Seidel, S. R., Stang, P. J., High-symmetry coordination cages via self-assembly. Acc. Chem. Res. 2002, 35, 972-983.

(9) Sullivan, L. H., The tall office building artistically considered. Lippincott's Magazine 1896, 403-409.

(10) (a) Rizzuto, F. J., Ramsay, W. J., Nitschke, J. R., Otherwise unstable structures self-assemble in the cavities of cuboctahedral coordination cages. J. Am. Chem. Soc. 2018, 140, 11502-11509; (b) Custelcean, R., Anion encapsulation and dynamics in self-assembled coordination cages. Chem. Soc. Rev. 2014, 43, 1813-1824; (c) Greenaway, R. L., Holden, D., Eden, E. G. B., Stephenson, A., Yong, C. W., Bennison, M. J., Hasell, T., Briggs, M. E., James, S. L., Cooper, A. I., Understanding gas capacity, guest selectivity, and diffusion in porous liquids. Chem. Sci. 2017, 8, 2640-2651.

(11) Chen, J., Körner, S., Craig, S. L., Lin, S., Rudkevich, D. M., Rebek, J., Chemical amplification with encapsulated reagents. Proc. Natl. Acad. Sci. U.S.A. 2002, 99, 2593-2596.

(12) (a) Levin, M. D., Kaphan, D. M., Hong, C. M., Bergman, R. G., Raymond, K. N., Toste, F. D., Scope and mechanism of cooperativity at the intersection of organometallic and supramolecular catalysis. J. Am. Chem. Soc. 2016, 138, 96829693; (b) Mondal, B., Mukherjee, P. S., Cage encapsulated gold nanoparticles as heterogeneous photocatalyst for facile and selective reduction of nitroarenes to azo compounds. J. Am. Chem. Soc. 2018, 140, 12592-12601; (c) Kang, J., Santamaría, J., Hilmersson, G., Rebek, J., Self-assembled molecular capsule catalyzes a Diels-Alder reaction. J. Am. Chem. Soc. 1998, 120, 7389-7390.

(13) (a) Ozores, H. L., Amorín, M., Granja, J. R., Self-assembling molecular capsules based on $\alpha, \gamma$-cyclic peptides. J. Am. Chem. Soc. 2017, 139, 776-784; (b) Sakata, Y., Murata, C., Akine, S., Anion-capped metallohost allows extremely slow guest uptake and on-demand acceleration of guest exchange. Nat. Commun. 2017, 8, 16005; (c) Petrosko, S. H., Johnson, R., White, H., Mirkin, C. A., Nanoreactors: Small spaces, big implications in chemistry. J. Am. Chem. Soc. 2016, 138, 7443-7445.

(14) Hong, S., Rohman, M. R., Jia, J., Kim, Y., Moon, D., Kim, Y., Ko, Y. H., Lee, E., Kim, K., Porphyrin boxes: Rationally designed porous organic cages. Angew. Chem. Int. Ed. 2015, 54, 1324113244.

(15) Bloch, W. M., Holstein, J. J., Hiller, W., Clever, G. H., Morphological control of heteroleptic cis- and trans- $\mathrm{Pd}_{2} \mathrm{~L}_{2} \mathrm{~L}_{2}$ cages. Angew. Chem. Int. Ed. 2017, 56, 8285-8289.

(16) Chakrabarty, R., Mukherjee, P. S., Stang, P. J., Supramolecular coordination: Self-assembly of finite two- and three-dimensional ensembles. Chem. Rev. 2011, 111, 68106918.

(17) (a) Greenfield, J. L., Rizzuto, F. J., Goldberga, I., Nitschke, J. R., Self-assembly of conjugated metallopolymers with tunable length and controlled regiochemistry. Angew. Chem. Int. Ed. 2017, 56, 7541-7545; (b) Li, S.-L., Xiao, T., Lin, C., Wang, L., Advanced supramolecular polymers constructed by orthogonal self-assembly. Chem. Soc. Rev. 2012, 41, 5950-5968; (c) Greenfield, J. L., Evans, E. W., Di Nuzzo, D., Di Antonio, M., Friend, R. H., Nitschke, J. R., Unraveling mechanisms of chiral induction in double-helical metallopolymers. J. Am. Chem. Soc. 2018, 140, 10344-10353.

(18) Miljanić, O. Š., Small-molecule systems chemistry. Chem 2017, 2, 502-524.

(19) (a) Piguet, C., Bernardinelli, G., Hopfgartner, G., Helicates as versatile supramolecular complexes. Chem. Rev. 1997, 97, 2005-2062; (b) Kai, S., Maddala, S. P., Kojima, T., Akagi, S., Harano, K., Nakamura, E., Hiraoka, S., Flexibility of components alters the self-assembly pathway of $\mathrm{Pd}_{2} \mathrm{~L}_{4}$ coordination cages. Dalton Trans. 2018, 47, 3258-3263.

(20) (a) Preston, D., Sutton, J. J., Gordon, K. C., Crowley, J. D., A nona-nuclear heterometallic $\mathrm{Pd}_{3} \mathrm{Pt}_{6}$ "donut"-shaped cage: Molecular recognition and photocatalysis. Angew. Chem. Int. Ed. 2018, 57, 8659-8663; (b) Mosquera, J., Ronson, T. K., Nitschke, J. R., Subcomponent flexibility enables conversion between $D_{4}$ symmetric $\mathrm{Cd}^{\mathrm{II}} \mathrm{L}_{8}$ and $\mathrm{T}$-symmetric $\mathrm{Cd}^{\mathrm{II}} \mathrm{L}_{4}$ assemblies. J. Am. Chem. Soc. 2016, 138, 1812-1815.

(21) (a) Jamieson, E. M. G., Modicom, F., Goldup, S. M., Chirality in rotaxanes and catenanes. Chem. Soc. Rev. 2018, 47, 5266-5311; (b) Kinney, Z. J., Hartley, C. S., Twisted macrocycles with folded ortho-phenylene subunits. J. Am. Chem. Soc. 2017, 139, 4821-4827.

(22) (a) Wang, Q.-Q., Day, V. W., Bowman-James, K., Chemistry and structure of a host-guest relationship: The power of NMR and X-ray diffraction in tandem. J. Am. Chem. Soc. 2013, 135, 392-399; (b) Eytel, L. M., Gilbert, A. K., Görner, P., Zakharov, L. N., Johnson, D. W., Haley, M. M., Do CH-anion and anion- $\pi$ interactions alter the mechanism of 2:1 host-guest complexation in arylethynyl monourea anion receptors? Chem. - Eur. J. 2017, 23, 4051-4054.

(23) (a) Young, M. C., Holloway, L. R., Johnson, A. M., Hooley, R. J., A supramolecular sorting hat: Stereocontrol in metalligand self-assembly by complementary hydrogen bonding. Angew. Chem. Int. Ed. 2014, 53, 9832-9836; (b) Meng, W., Ronson, T. K., Nitschke, J. R., Symmetry breaking in selfassembled $\mathrm{M}_{4} \mathrm{~L}_{6}$ cage complexes. Proc. Natl. Acad. Sci. U.S.A. 2013, 110, 10531-10535.

(24) (a) Caprice, K., Pupier, M., Kruve, A., Schalley, C. A., Cougnon, F. B. L., Imine-based [2] catenanes in water. Chem. Sci. 2018, 9, 1317-1322; (b) Lee, H., Noh, T. H., Jung, O.-S., Construction of hetero-four-layered tripalladium(II) cyclophanes by transannular $\pi \cdots \pi$ Interactions. Angew. Chem. Int. Ed. 2016, 55, 1005-1009.

(25) (a) Barnes, J. C., Fahrenbach, A. C., Cao, D., Dyar, S. M., Frasconi, M., Giesener, M. A., Benítez, D., Tkatchouk, E., Chernyashevskyy, O., Shin, W. H., Li, H., Sampath, S., Stern, C. L., Sarjeant, A. A., Hartlieb, K. J., Liu, Z., Carmieli, R., Botros, Y. Y., Choi, J. W., Slawin, A. M. Z., Ketterson, J. B., Wasielewski, M. R., Goddard, W. A., Stoddart, J. F., A radically configurable six-state compound. Science 2013, 339, 429-433; (b) Wang, Y., Frasconi, M., Stoddart, J. F., Introducing stable radicals into molecular machines. ACS Cent. Sci. 2017, 3, 927-935.

(26) (a) Li, Y., Handke, M., Chen, Y.-S., Shtukenberg, A. G., Hu, C. T., Ward, M. D., Guest exchange through facilitated transport in a seemingly impenetrable hydrogen-bonded framework. $J$. 
Am. Chem. Soc. 2018, 140, 12915-12921; (b) Jo, J., Olasz, A., Chen, C.-H., Lee, D., Interdigitated hydrogen bonds: Electrophile activation for covalent capture and fluorescence turn-on detection of cyanide. J. Am. Chem. Soc. 2013, 135, 3620-3632; (c) Spengler, M., Dong, R. Y., Michal, C. A., Hamad, W. Y., MacLachlan, M. J., Giese, M., Hydrogen-bonded liquid crystals in confined spaces-toward photonic hybrid materials. Adv. Funct. Mater. 2018, 28, 1800207; (d) Huo, F., Xu, H., Zhang, L., Fu, Y., Wang, Z., Zhang, X., Hydrogen-bonding based multilayer assemblies by self-deposition of dendrimer. Chem. Commun. 2003, 874-875; (e) Sijbesma, R. P., Beijer, F. H., Brunsveld, L., Folmer, B. J. B., Hirschberg, J. H. K. K., Lange, R. F. M., Lowe, J. K. L., Meijer, E. W., Reversible polymers formed from selfcomplementary monomers using quadruple hydrogen bonding. Science 1997, 278, 1601-1604; (f) Blight, B. A., Hunter, C. A., Leigh, D. A., McNab, H., Thomson, P. I. T., An AAAA-DDDD quadruple hydrogen-bond array. Nat. Chem. 2011, 3, 244.

(27) (a) van Gorp, J. J., Vekemans, J. A. J. M., Meijer, E. W., $C_{3}$ symmetrical supramolecular architectures: Fibers and organic gels from discotic trisamides and trisureas. J. Am. Chem. Soc. 2002, 124, 14759-14769; (b) Thota, B. N. S., Lou, X., Bochicchio, D., Paffen, T. F. E., Lafleur, R. P. M., van Dongen, J. L. J., Ehrmann, S., Haag, R., Pavan, G. M., Palmans, A. R. A., Meijer, E. W., Supramolecular copolymerization as a strategy to control the stability of self-assembled nanofibers. Angew. Chem. Int. Ed. 2018, 57, 6843-6847; (c) Stals, P. J. M., Everts, J. C., de Bruijn, R., Filot, I. A. W., Smulders, M. M. J., Martín-Rapún, R., Pidko, E. A., de Greef, T. F. A., Palmans, A. R. A., Meijer, E. W., Dynamic supramolecular polymers based on benzene-1,3,5tricarboxamides: The influence of amide connectivity on aggregate stability and amplification of chirality. Chem. - Eur. J. 2010, 16, 810-821.

(28) Meng, W., Clegg, J. K., Thoburn, J. D., Nitschke, J. R., Controlling the transmission of stereochemical information through space in terphenyl-edged Fe 4 L6 cages. J. Am. Chem. Soc. 2011, 133, 13652-13660.

(29) (a) Lacour, J., me, Ginglinger, C., Grivet, C., Bernardinelli, G., Synthesis and resolution of the configurationally stable tris(tetrachlorobenzenediolato)phosphate(V) ion. Angew.
Chem. Int. Ed. 1997, 36, 608-610; (b) Lacour, J., Ginglinger, C., Favarger, F., Torche-Haldimann, S., Application of TRISPHAT anion as NMR chiral shift reagent. Chem. Commun. 1997, 22852286.

(30) (a) Liu, M., Zhang, L., Wang, T., Supramolecular chirality in self-assembled systems. Chem. Rev. 2015, 115, 7304-7397; (b) Wang, Y., Fang, H., Tranca, I., Qu, H., Wang, X., Markvoort, A. J., Tian, Z., Cao, X., Elucidation of the origin of chiral amplification in discrete molecular polyhedra. Nat. Commun. 2018, 9, 488.

(31) (a) Siegel, J. S., Homochiral imperative of molecular evolution. Chirality 1998, 10, 24-27; (b) Mislow, K., Siegel, J., Stereoisomerism and local chirality. J. Am. Chem. Soc. 1984, 106, 3319-3328.

(32) Kramer, R., Lehn, J. M., Marquis-Rigault, A., Selfrecognition in helicate self-assembly: Spontaneous formation of helical metal complexes from mixtures of ligands and metal ions. Proc. Natl. Acad. Sci. U.S.A. 1993, 90, 5394-5398.

(33) Wagner, G., Pardi, A., Wuethrich, K., Hydrogen bond length and proton NMR chemical shifts in proteins. J. Am. Chem. Soc. 1983, 105, 5948-5949.

(34) (a) Das, A., Vantomme, G., Markvoort, A. J., ten Eikelder, H. M. M., Garcia-Iglesias, M., Palmans, A. R. A., Meijer, E. W., Supramolecular copolymers: Structure and composition revealed by theoretical modeling. J. Am. Chem. Soc. 2017, 139, 7036-7044; (b) Smulders, M. M. J., Schenning, A. P. H. J., Meijer, E. W., Insight into the mechanisms of cooperative selfassembly: The "Sergeants-and-Soldiers" principle of chiral and achiral $\mathrm{C}_{3}$-symmetrical discotic triamides. J. Am. Chem. Soc. 2008, 130, 606-611.

(35) Garcia, A. M., Iglesias, D., Parisi, E., Styan, K. E., Waddington, L. J., Deganutti, C., De Zorzi, R., Grassi, M., Melchionna, M., Vargiu, A. V., Marchesan, S., Chirality effects on peptide self-assembly unraveled from molecules to materials. Chem 2018, 4, 1862-1876.

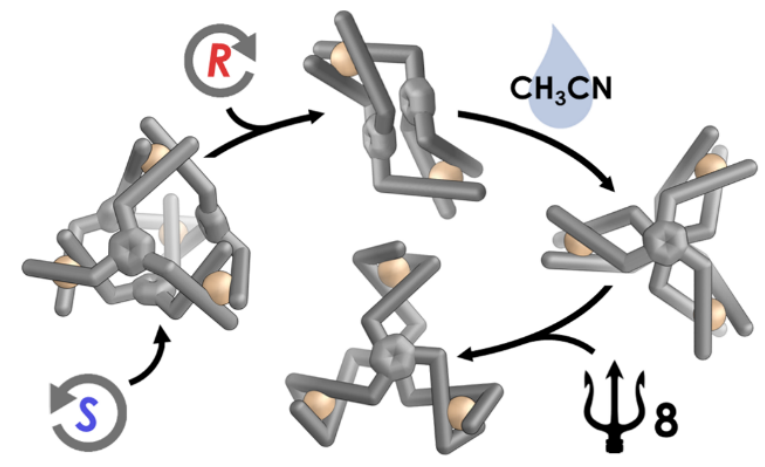

